\title{
Adoção do Padrão IRFS no Brasil: Impacto do Custo Atribuído no Grau de Endividamento (GE) e no Retorno Sobre o Ativo (RSA) das Empresas
}

\section{Resumo}

A adoção das normas internacionais de contabilidade no Brasil permitiu que empresas avaliassem itens do ativo imobilizado ao valor justo, utilizando o deemed cost (custo atribuído), como procedimento autorizado a emprestar nova tradução monetária a esses itens, tendo como contrapartida o patrimônio líquido e eventuais reflexos no passivo. Essa permissão foi restrita ao ano da adoção inicial ao padrão International Financial Reporting Standards (IFRS), sendo vedado seu uso para períodos subsequentes. Como a atualização monetária do custo dos ativos não monetários das empresas havia sido revogada há mais de uma década, a adoção do custo atribuído sinalizaria uma possibilidade de recomposição de valor e que esse procedimento poderia alterar a magnitude dos indicadores estruturais do estado patrimonial das empresas. Nesse contexto, o objetivo do artigo é investigar e evidenciar se a utilização do custo atribuído pelas empresas brasileiras listadas na BM\&, na adoção inicial do padrão IFRS, no exercício de 2009, alterou, significativamente, o quantum dos indicadores estruturais Grau de Endividamento (GE) e Retorno sobre o Ativo (RSA). Para a obtenção dos resultados, foram utilizados modelos quantitativos sustentados na análise da variância por meio de teste de médias, na matriz de correlação de Pearson e nas estatísticas descritivas. Os resultados, com confiança de 95\%, sugerem que, estatisticamente, a utilização do custo atribuído no Brasil não foi atrativa para as empresas, não produziu alterações significativas no Grau de Endividamento (GE) e no Retorno sobre Ativo (RSA) e não revelou subavaliação significativa dos ativos fixos corporativos.

Palavras-chaves: Valor Justo, Custo Atribuído, Grau de Endividamento (GE), Retorno sobre o Ativo (RSA), Adoção do Padrão IFRS.

\section{José Antonio de França Doutor pela Universidade de Brasília (UnB), Professor Adjunto da Universidade de Brasília (UnB). Contato: Campus Darcy Ribeiro, Asa Norte, Brasília, DF, CEP: 70910-970. E-mail: franca@itecon.com.br}

George Henrique de Moura Cunha Doutor pela Universidade de Brasília (UnB), Diretor do Departamento de Economia da Universidade Católica de Brasília (UCB). Contato: Campos de Águas Claras, Pistão Sul, Águas Claras, DF, CEP: 71966-700. E-mail: george@ucb.br

\section{Daniel Pereira Cunha}

Especialista pela Universidade de Brasília (UnB) e Bancário. Contato: SIA 3, número 260, SIA, Brasília, DF, CEP: 70000-000. E-mail: daniel.p.cunha@caixa.gov.br 


\section{Introdução}

O presente artigo traz para discussão as conclusões de um estudo comparativo dos indicadores estruturais denominados Grau de Endividamento (GE) e Retorno sobre o Ativo (RSA), calculados com base nas demonstrações contábeis padronizadas do exercício findo em 2009, de uma amostra de 57 empresas brasileiras listadas na BM\&Bovespa, que utilizaram o deemed cost (custo atribuído), por ocasião da adoção inicial do padrão IFRS (International Financial Reporting Standards).

O custo atribuído, conforme conceitua o Apêndice A do Pronunciamento Técnico CPC 37 (R1) (CPC, 2010a), é o montante utilizado como substituto para o custo (ou custo depreciado ou amortizado) em determinada data. A precificação do custo atribuído depende do modelo eleito, que pode ser o valor de mercado reduzido das despesas de venda ou o valor de uso, que corresponde ao fluxo de caixa descontado dos benefícios projetados por todo o restante da vida economicamente útil do bem. A proposta de pesquisa que resultou no presente artigo não contempla investigar qual dos dois métodos a empresa utilizou na precificação do custo atribuído.

A permissão para utilizar o custo atribuído foi a oportunidade esperada pelas empresas brasileiras tributadas pela modalidade do lucro real para reavaliar itens de seu ativo imobilizado pelo fair value (valor justo), já que, por mais de uma década, o mecanismo de correção monetária de balanço, que permitia incorporar a inflação ao custo dos ativos, havia sido revogado, como preceitua a Lei n. ${ }^{\circ} 9.249$ (1995). O referido mecanismo revogado de correção monetária de balanço contemplava a atualização monetária dos itens não monetários, incorporando os efeitos da inflação a si próprios, com a contrapartida no resultado. Nesse contexto, então, a permissão para utilizar do custo atribuído poderia estar sustentada na premissa de que os ativos não monetários das empresas brasileiras poderiam estar subavaliados em função da perda de valor pela não incorporação do processo inflacionário.

As empresas que compõem a amostra divulgaram em suas demonstrações financeiras padronizadas comparativas do exercício de 2010 a utilização do mecanismo do custo atribuído no exercício de 2009, cujos dados foram tabulados e comparados para permitir o cálculo dos indicadores estruturais Grau de Endividamento (GE) e Retorno sobre o Ativo (RSA), nos cenários com e sem os efeitos do custo atribuído.

Como é conhecido, o processo de adoção do padrão International Financial Reporting Standards (IFRS) exige modificações significativas na forma de comunicação e no conteúdo das informações financeiras constantes das demonstrações contábeis padronizadas. Essas modificações são exigidas tanto na estrutura das demonstrações financeiras quanto no preparo e forma de divulgação, sob a perspectiva de melhoria da qualidade das informações que subsidiam o processo de tomada de decisões no âmbito geral dos negócios.

Focados na necessidade de produzir informações confiáveis e comparáveis, de reduzir assimetrias existentes entre as práticas contábeis globais recomendadas pelo International Accounting Standards Board (IASB) e as práticas domésticas, países como o Brasil e outros migraram para o modelo único de contabilidade regulada e sustentada no padrão IFRS.

No Brasil, o Conselho Federal de Contabilidade (CFC), por meio do Comitê de Pronunciamentos Contábeis (CPC), compartilha com outras instituições reguladoras a adoção às normas internacionais de contabilidade. A partir desse compartilhamento, o CPC vem emitindo pronunciamentos que são submetidos à apreciação e aprovação dos principais órgãos reguladores do mercado brasileiro desde 2008, quando então esses pronunciamentos adquirem o status de normas.

Entre essas normas, a pesquisa foca a oriunda do Pronunciamento 37 (R1) (CPC, 2010a) e da Interpretação ICPC 10 (CPC, 2009b), que trata de diversas isenções que podem ser aplicadas no período de transição à norma internacional, como a do custo atribuído, alinhada com a IFRS 01 - First Time Adoption of International Financial Reporting Standard (IASB, 2012)

Essa estrutura normativa permite a adoção do custo atribuído para tradução ao valor justo dos itens do ativo imobilizado e os da propriedade para investimento na fase de transição para o padrão internacional. Porém, este artigo somente aborda a adoção do custo atribuído ao ativo imobilizado. 
A tradução monetária dos ativos ao custo atribuído implica reconhecer o valor justo desses ativos na data da adoção inicial. O IASB (2003), por meio da IFRS 1, conceitua valor justo como sendo o valor de uma transação entre partes conhecedoras e interessadas no negócio em uma operação sem favorecimentos. Esse reconhecimento trata de corrigir o valor de livro dos bens, levando em consideração sua provável geração de caixa, cujo valor contábil seja, significativamente, inferior ou superior ao valor justo mensurado na data do reconhecimento, que o Brasil implementou no exercício de 2009. Esse procedimento, por permitir incorporar a mais valia do item do ativo em sentido positivo ou negativo, difere do padrão revogado em que somente era permitida a incorporação da mais valia quando a diferença entre o valor da nova tradução monetária do item e seu valor de custo fosse positiva.

Acredita-se que a adoção do valor justo, na data de transição à norma internacional de contabilidade, para os itens do ativo imobilizado, poderia ser significativa, considerando que o procedimento visa corrigir disparidades construídas ao longo da vida útil desses itens, provocadas por (a) ausência de incorporação das taxas de inflação no período de mais de uma década e (b) utilização de taxas de depreciação para fins fiscais, com a finalidade de reconhecer perdas econômicas pelo uso.

Embora a permissão de utilizar o custo atribuído seja direcionada para atender a um fim específico de ajuste ao valor justo, a literatura evidencia que escolhas contábeis são por vezes utilizadas para atender também a outras finalidades, as quais são mais convenientes às empresas em geral, como mostram Fields, Lys e Vincent (2000). Sabendo que a aplicação do custo atribuído implicaria uma variação de preço no ativo, distribuída em contrapartida no patrimônio líquido e, por reflexos tributários, no passivo, e ainda um provável reconhecimento no resultado, essa aplicação poderia impactar os indicadores estruturais Grau de Endividamento (GE) e Retorno sobre o Ativo (RSA) das empresas.

Nesse contexto, o artigo tem como objetivo investigar e evidenciar se a utilização do custo atribuído pelas empresas brasileiras listadas na BM\&Bovespa, na adoção inicial do padrão IFRS, no exercício de 2009, alterou, significativamente, o quantum dos indicadores estruturais Grau de Endividamento (GE) e Retorno sobre o Ativo (RSA). Para cumprimento desse objetivo, utiliza-se metodologia positivista sustentada em técnicas estatísticas para responder à seguinte questão de pesquisa: O Grau de Endividamento (GE) e o Retorno sobre o Ativo (RSA) das empresas brasileiras listadas na BM\&Bovespa, que utilizaram o custo atribuído na adoção inicial do padrão IFRS no Brasil, foram, significativamente, afetados?

Como expectativa de resposta, é razoável esperar que o Grau de Endividamento (GE) e o Retorno sobre o Ativo (RSA), na forma alternativa, apresentem o seguinte comportamento:

$\mathbf{H}_{1}$ : O GE e o RSA com a incorporação do custo atribuído aos itens do ativo imobilizado são estatisticamente diferentes, em média, dos GE e RSA sem a adoção do custo atribuído.

Nesse contexto, considerando o processo inflacionário brasileiro não incorporado às demonstrações contábeis das empresas por mais de uma década, e o uso de taxas de depreciação para fins fiscais, para medir a vida economicamente útil dos itens do ativo, parece razoável esperar que a adoção do custo atribuído possa corrigir essas anomalias de valores e, como consequência, produzir alterações significativas nos valores do ativo e do patrimônio líquido das empresas.

A escolha do exercício de 2009 foi exercida em função de grande parte das empresas ter optado por antecipar a adoção inicial ao padrão IFRS no Brasil, prevista para ocorrer no exercício social iniciado em $1^{0}$ de janeiro de 2010.

Já a escolha do Grau de Endividamento (GE) e do Retorno sobre o Ativo (RSA), como as únicas variáveis a serem testadas pela pesquisa, justifica-se porque o GE captura a mudança na relação do endividamento provocada pelas alterações nos valores do ativo e da dívida de longo prazo em proporções diferentes, e porque o RSA captura a mudança na rentabilidade provocada pelo ajuste da depreciação levada ao resultado. Essas características das duas variáveis são suficientes medir as alterações provocadas pela utilização do custo atribuído no estado patrimonial das empresas e, em função disso, a mensuração é feita antes e depois da adoção. 


\section{Discussão Teórica}

Embora outros trabalhos que, de forma indireta, apresentam relacionamento com o objeto da pesquisa tenham sido investigados, esta seção traz para discussão somente aqueles que contêm contribuições relevantes.

\subsection{Escolhas Contábeis}

A decisão de utilizar o custo atribuído como procedimento para ajustar o valor de itens do ativo imobilizado ao valor de mercado, por ocasião da adoção inicial do padrão IFRS, pode ser entendida como uma escolha contábil. Uma escolha contábil é qualquer decisão em que se objetiva influenciar, pela forma ou pela substância, a saída do sistema contábil de uma maneira específica. Nela se inclui não somente informações oriundas das demonstrações financeiras, mas também fatores como a mensuração de tributos e a percepção de órgãos reguladores. Essas escolhas são influenciadas por imperfeições de mercado, como custos de agência relativos a questões contratuais, assimetria da informação geralmente associada à relação entre gestores e os investidores e, ainda, fatores externos que interferem nas relações com terceiros, como a melhoraria na capacidade de endividamento estudada por Fields, Lys e Vincent (2000).

Outras influências, como a contratual nas escolhas contábeis, visam reduzir restrições com o objetivo de maximizar o bem-estar dos gestores, como evidenciam Heflin, Kwon e Wild (2002). Cabe ainda destacar que escolhas contábeis não levam em consideração somente a influência nos resultados das empresas. Watts (1992) expõe que, embora as escolhas possam influenciar o resultado, nem todas as escolhas contábeis compreendem o gerenciamento de resultado, pois o gerenciamento pode ser uma das formas de aproveitar alternativas existentes nas normas para intervir propositadamente no reporte financeiro com a intenção de obter vantagem.

O estudo de Waweru, Ntui e Mangena (2010) corrobora a posição de Watts (1992), pois por eles foram identificadas diversas escolhas que afetam o resultado, dentre as quais foi destacada a necessidade de financiamento como fonte direcionadora de escolhas contábeis.

\subsection{Reavaliação de Ativos e o Grau de Endividamento}

Reavaliação positiva do ativo imobilizado é um assunto controverso na pesquisa contábil, assim como no processo de convergência contábil às normas internacionais de contabilidade, como mostram Lopes e Walker (2010). O CPC 27 (CPC, 2009a) mantém o custo histórico como base de valoração do ativo imobilizado, sendo previsto nele o procedimento de reavaliação quando permitido pela norma local. No caso do Brasil, por força da Lei n. ${ }^{\circ} 11.638$ (2007), essa prática foi revogada.

A interpretação técnica ICPC 10 (Interpretação sobre a Aplicação Inicial ao Ativo Imobilizado e à Propriedade para Investimento dos Pronunciamentos Técnicos CPCs 27, 28, 37 e 43) (CPC, 2009b), recomenda a aplicação do custo atribuído na adoção inicial às normas internacionais de contabilidade. Em função dessa recomendação, vê-se o custo atribuído como uma escolha contábil, como em Missonier-Piera (2007), por ser uma espécie de reavaliação de ativos. No Brasil, o custo atribuído encerra o ciclo dos procedimentos de reavaliação de ativos. Na literatura, inúmeros autores investigaram em diversos períodos a reavaliação de ativos e suas motivações, como as de conhecer a relação entre o grau de endividamento e a reavaliação de ativos.

Estudos sobre a reavaliação de ativos associaram o incentivo do aumento da capacidade de endividamento ao uso desta prática, como demonstram Brown, Izan e Loh (1992); Easton, Eddey e Harris (1993); e Lopes e Walker (2010). A reavaliação de ativos, apesar de seu custo de implementação e do efeito nulo em caixa, fora objeto de pesquisa na Austrália, e os resultados mostraram que ela está relacionada com o potencial de afetar os custos políticos, assimetria informacional e contratação de empréstimos, como mostram Brown, Izan e Loh (1992). 
Ainda na Austrália, uma das motivações da pesquisa de Cotter (1999) foi investigar a correlação entre a prática de reavaliação de ativo e o endividamento das empresas. Os resultados da pesquisa mostram que a relação entre a prática da reavaliação de ativos e o endividamento vem diminuindo ao longo do tempo devido a uma maior ênfase em financiamentos em bancos, menores taxas de inflação e custo provocado por exigências legais de reavaliações periódicas a cada três anos. Evidencia ainda que os custos da reavaliação, no contexto australiano daquela pesquisa, parecem superar a redução dos custos das dívidas.

Custos políticos e necessidade de financiamentos (endividamento) foram abordados por Barlev, Fried, Haddad e Livnat (2007), quando investigaram a correlação entre o desempenho futuro e a utilização da reavaliação de ativos em trinta e cinco países (entre eles o Brasil), e os resultados obtidos sugerem que os direcionadores nas escolhas contábeis são diferentes, conforme as características do país em que a empresa atua.

Na Suíça, Missonier-Piera (2007) observou que empresas com maior grau de alavancagem são mais propensas a adotar a reavaliação positiva de ativos no sentido de sinalizar melhor capacidade de endividamento e reduzir o risco de descumprimento de exigências em contratos de dívida.

No Brasil, de acordo com Lopes e Walker (2010), a reavaliação de ativos é negativamente relacionada ao desempenho das empresas. Os autores concluem que a adoção da reavaliação de ativos, embora contribua para mostrar melhor estrutura de endividamento, pode ser influenciada pelo impacto negativo no cálculo do dividendo mínimo sobre o lucro líquido.

Na França, Cazavan-Jeny e Jeanjean (2007) investigaram o efeito da adoção das IFRS e observaram que as companhias tendem a fazer escolhas contábeis que melhorem o seu grau de endividamento.

\subsection{A adoção do Deemed Cost}

Como já exposto, a aplicação do valor justo a itens do imobilizado, por meio do custo atribuído, é uma exceção justificada pelo advento da adoção do padrão IFRS no Brasil. Essa adoção corrige as defasagens valorativas de itens de bens do ativo fixo, ajustando-os de maneira positiva ou negativa.

De acordo com o Parlamento Europeu e Conselho da União Europeia (2002) e ICAEW (2007), no âmbito da União Europeia, empresas com ações negociadas em bolsas de valores apresentam, obrigatoriamente, suas demonstrações financeiras em IFRS desde o ano de 2005. Sendo este continente o berço das normas internacionais, foi também o primeiro a aplicá-las integralmente. De lá, algumas pesquisas relacionadas à adesão do custo atribuído e à adoção inicial dessas normas foram desenvolvidas, como podem ser verificadas nas abordagens seguintes.

Christensen e Nikolaev (2008) investigaram as empresas do Reino Unido e Alemanha que utilizaram o fair value (valor justo) no ano da adoção obrigatória do padrão IFRS. O resultado de suas pesquisas mostra que nesses dois países as empresas são menos propensas a valorizar os ativos por meio do fair value, quando há também opção pelo custo histórico. Consequentemente, nesses dois países, a adoção do deemed cost alcançou um número pequeno de empresas em termos percentuais.

A pesquisa conduzida por Cazavan-jeny e Jeanjean (2007) mostra que, na França, a adoção do custo atribuído ocorreu em, aproximadamente, $20 \%$ das empresas listadas no índice da Sociétédes Bourses Françaises (SBF 120). Esse resultado é corroborado por Demaria e Dufour (2007) ao estudar a escolha do valor justo pelas empresas durante a adoção do padrão IFRS, como método de avaliação do ativo imobilizado. Seus resultados também concluíram que grande parte das empresas manteve a opção conservadora pelo custo histórico ao invés da opção de traduzir o custo ao valor justo, como admitido pela IFRS 1.

$\mathrm{Na}$ Espanha, a adoção do custo atribuído para os ativos imobilizados foi feita por 23\% das companhias não financeiras integrantes do Spanish Continuous Market, ou ainda por 33\% dos casos aplicáveis da amostra, descontadas as companhias em que a isenção não se aplica ou não foi divulgada, como mostram Aledo, García-Martínez e Diazaraque (2009). 
Estudando o uso do fair value na comparabilidade das demonstrações financeiras publicadas por empresas da Austrália e Reino Unido no ano da adoção inicial das IFRS, Cairns, Massoudi, Taplin e Tarca (2011) observaram um baixo uso desse tipo de valorização e sugeriram que os gestores julgam a avaliação ao custo histórico mais adequada na valoração do ativo imobilizado. Ainda Cairns et al. (2011) avaliaram a adoção do custo atribuído e verificaram que, apesar da possível atratividade da aplicação do valor justo durante a transição, sem a obrigatoriedade de reavaliações periódicas, a maioria das empresas não utilizou essa isenção.

O ativo imobilizado também foi objeto de relevante estudo apresentado pela Comissão Européia (2007). No que tange ao IFRS 1, algumas empresas aplicaram o custo atribuído, todavia na amostra predominou o uso do custo histórico como base de valoração desses ativos pelas empresas do continente europeu.

\section{Sustentação Metodológica}

As informações contábeis sem o custo atribuído do exercício findo em 2009, das firmas listadas na BM\&Bovespa, foram recuperadas das demonstrações contábeis depositadas no repositório da consultoria Economática, e as informações com o custo atribuído foram acessadas das demonstrações contábeis padronizadas comparativas do exercício de 2010 depositadas no site da BM\&Bovespa. A identificação da utilização do custo atribuído na adoção inicial do padrão IFRS pelas firmas listadas constantes da amostra foi obtida por meio da leitura das informações divulgadas nas notas explicativas. O tratamento inicial dos dados consistiu em segregar das demonstrações contábeis comparativas o ativo, o passivo e o lucro do período, com e sem o custo atribuído e organizá-los por empresa para permitir a alimentação do pacote estatístico gretl utilizado para os cálculos.

\subsection{Descrição do Modelo}

A técnica analítica adotada para o tratamento das variáveis que o modelo pretende explicar é capaz de fornecer respostas suficientes para testar as relações entre as variáveis da pesquisa, Grau de Endividamento (GE) e Retorno sobre o Ativo (RSA), utilizando-se a análise da variância por meio do teste de médias, da estatística Fe da matriz de correlação de Pearson como em Bruni (2011), Missio e Jacobi (2007).

Inicialmente, para obter o comportamento da amostra, foram calculadas as estatísticas descritivas, cujos resultados encontram-se analisados na seção 4 .

Para mensurar o impacto que o custo atribuído possa ter provocado nos indicadores estruturais Grau de Endividamento (GE) e Retorno sobre o Ativo (RSA), utiliza-se o modelo de teste de médias representado pela equação 1 seguinte, cujos resultados finais estão analisados na seção 4.

$$
\text { Estatística }_{\text {teste }}=\frac{\bar{x}_{1}-\bar{x}_{2}}{\sqrt[2]{\frac{s_{1}^{2}}{n_{1}}+\frac{s_{2}^{2}}{n_{2}}}}
$$

Onde:

Onde $\bar{x}_{1}$ é a média do GE; $\bar{x}_{2}$ é a média do RSA; $\mathrm{s}_{1}^{2}$ é a variância da média do GE; $\mathrm{s}_{2}^{2}$ é a variância RSA; $n_{1}$ é a quantidade de observações do GE; e $n_{2}$ é a quantidade de observações do RSA. As variáveis do modelo representam os cenários com e sem o custo atribuído. 
Para corroborar os resultados do teste produzido pelo modelo da equação 1, utiliza-se o teste $F$ para a análise de variância de um fator, cujo modelo se demonstra na equação 2 seguinte.

$$
\text { Estatística }_{F}=\frac{S_{\pi c d c}^{2}}{S_{\pi s d c}^{2}}
$$

Onde:

$S^{2}$ é a variância do indicador estrutural GE ou RSA; $\pi$ é o indicador estrutural GE ou RSA; cdc é a indicação de utilização do custo atribuído; sdc é a indicação não utilização do custo atribuído.

O Retorno Sobre o Ativo (RSA) é obtido pela relação entre o lucro líquido $(\pi)$ e o valor total do Ativo (A), como demonstrado na equação 3 .

$$
\mathrm{RSA}=\frac{\pi}{\mathrm{A}}
$$

O Grau de Endividamento (GE) é obtido pela relação entre a soma do Passivo Circulante (PC) com o Passivo Não Circulante (PNC) e o valor total do Ativo (A), como demonstrado na equação 4.

$$
\mathrm{GE}=\frac{(\mathrm{PC}+\mathrm{PNC})}{\mathrm{A}}
$$

A correlação entre as variáveis com e sem o impacto do custo atribuído é obtida por meio da matriz de correlação de Pearson, conforme modelo demonstrado na equação 5.

$$
r=\frac{n\left(\sum \mathrm{GE} \times \mathrm{RSA}\right)-\sum \mathrm{GE} \times \mathrm{RSA}}{\sqrt{\sqrt{n \mathrm{GE}^{2}-\left(\sum \mathrm{RSA}\right)^{2}} \times \sqrt{n \sum \mathrm{GE}^{2}-\left(\sum \mathrm{RSA}\right)^{2}}}}
$$

\subsection{Modelo Teórico do Custo Atribuído}

Conceitualmente o custo atribuído, como declarado no apêndice A do Pronunciamento técnico 37, pode ser modelado como sendo o valor realizável líquido, ou seja, o valor de mercado menos as despesas de venda, ou como o valor de uso do bem. O valor de mercado, singelamente, pode ser obtido no mercado ativo onde o item seja negociado. O valor de uso depende da obtenção do fluxo de caixa descontado a valor presente. Mas, para a obtenção do fluxo de caixa a valor presente, é necessário que o avaliador tenha conhecimento do restante da vida economicamente útil do bem para projetar os benefícios futuros e eleger uma taxa de desconto que seja compatível com o retorno do negócio. Nesse contexto, o modelo analítico para mensuração do valor a ser utilizado como custo atribuído pode ser obtido conforme proposição das equações 6 e 7. A equação 6 modela o custo atribuído por meio da diferença entre o valor de mercado e as despesas exigidas para venda, onde se obtém a identidade com o valor realizável líquido.

$$
C A \equiv V R L=V M 2-D V
$$

Onde:

CA é o custo atribuído; VRL é o valor realizável líquido do bem (entrada de caixa); VM é o valor que o mercado se dispõe a pagar pelo bem; DV é a despesa exigida para a venda do bem. 
A equação 7 modela o custo atribuído por meio da soma do fluxo de caixa projetado, descontado a valor presente, utilizando uma taxa que melhor represente o custo de oportunidade de manutenção do bem.

$$
C A \equiv F C_{d}=\frac{F C_{1}}{(1+i)^{1}}+\frac{F C_{2}}{(1+i)^{2}}+\ldots+\frac{F C_{n}}{(1+i)^{n}}
$$

Onde:

CA é o custo atribuído; $\mathrm{FC}_{\mathrm{d}}$ é o fluxo de caixa descontado; i é a taxa de desconto; $\mathrm{n}$ é o número de períodos da vida economicamente útil do bem.

A mais valia (MV) do custo atribuído a ser incorporada ao item do ativo é obtida por meio da diferença entre o valor contábil (VC) e o custo atribuído (CA), como mostrado na equação 8 seguinte.

$$
M V=[V C-C A]^{ \pm}
$$

Substituindo (6) ou (7) em (8) obtém-se a mais valia ou a menos valia a ser reconhecida na adoção inicial. Esse reconhecimento impactará o valor de custo do item do ativo, aumentando-o ou reduzindo-o, sensibilizando o patrimônio líquido pela contrapartida, em sentido inverso ao do item. Se o impacto for de aumento e dependendo da espécie do item avaliado, poderá ocorrer aumento do passivo tributário diferido.

\subsection{Amostra}

A amostra é constituída de um quantitativo de 57 empresas que sinalizaram, por meio de suas demonstrações financeiras padronizadas do exercício findo em 2009, ter utilizado o custo atribuído na adoção inicial do padrão IFRS no Brasil. Esse quantitativo de empresas que sinalizaram ter utilizado o custo atribuído na adoção inicial do padrão IFRS no Brasil corresponde aproximadamente a 15\% do total das empresas listadas BM\&Bovespa, percentual que acompanha a tendência mundial como mostram os achados de Aledo, García-Martínez e Diazaraque (2009), Christensen e Nikolaev (2008), Cairns et al. (2011), Cazavan-Jeny e Jeanjean (2007).

Considerando a permissão da ICPC 10 (CPC, 2009b), para recuperar as demonstrações financeiras padronizadas das empresas que utilizaram o custo atribuído no exercício de 2009, foi feita a leitura das notas explicativas referentes ao imobilizado e às práticas contábeis, verificando os termos relacionados a essa isenção (atribuído, deemed, justo, reavaliado), para os casos em que não foi divulgada esta informação entre as isenções utilizadas.

Os dados primários são formados pelo Ativo Total, Passivo Total e Lucro Líquido do período, com e sem utilização do custo atribuído. A partir desses dados, foram calculados o Grau de Endividamento (GE) e o Retorno sobre o Ativo (RSA), utilizados na alimentação dos modelos. Os dados referentes ao GE e o RSA da amostra, com e sem o custo atribuído, estão demonstrados no Apêndice.

\section{Análises e Apuração dos Resultados}

Utilizando os modelos e a amostra descritos na seção precedente, nesta seção estão demonstrados os cálculos da variabilidade dos dados, o relacionamento entre as variáveis, a análise e a discussão dos resultados obtidos com a aplicação dos modelos quantitativos.

Como resultado preliminar, a matriz de correlação das variáveis demonstradas na Tabela 1 sinaliza a presença de relacionamento direto entre os GEs com e sem a adoção do custo atribuído, da ordem de $95,46 \%$, sugerindo que o sentido do crescimento desse indicador em ambos os cenários, com e sem o custo atribuído, é positivo. Contudo, o relacionamento entre o GE e o RSA, nos dois cenários, com e sem o custo 
atribuído, mostra-se inverso e com intensidade média, variando entre -32,67\% e -36,04\%, mostrando que independentemente da utilização do custo atribuído, o relacionamento entre RSA e GE já se comportava em sentido oposto. Quando comparados os crescimentos do RSA com e sem o custo atribuído, verifica-se um comportamento direto da ordem de $97,74 \%$, semelhante ao comportamento dos GEs nas mesmas condições. O comportamento da relação inversa dos crescimentos do GE e RSA, de -32,67\% para -36,04\%, indica que a maior parcela da mais valia do custo atribuído, como poderia ser esperado, ficou alocada no patrimônio líquido e, consequentemente, menor quantia desse valor foi reconhecida no passivo tributário. Por outro lado, o relacionamento direto de $97,74 \%$ entre o RSA, com e sem o custo atribuído, também sugere que, mantido o desempenho das empresas, em média, o acréscimo ao ativo com a adição do custo atribuído não foi relevante o suficiente para reduzir, de forma significativa, a taxa de retorno.

Tabela 1

Matriz de Correlação do GE e do RA

\begin{tabular}{lllll}
\hline GEsdc & GEcdc & RSAsdc & RSAcdc \\
\hline 1,0000 & 0,9546 & $-0,3604$ & $-0,3483$ & GEsdc \\
\hline & 1,0000 & $-0,3480$ & $-0,3267$ & GEcdc \\
\hline & & 1,0000 & 0,9774 & RSAsdc \\
\hline
\end{tabular}

Obs.: GEsdc = grau de endividamento sem deemed cost; GEcdc = grau de endividamento com deemed cost; RSAsdc = retorno sobre o ativo sem deemed cost; RSAcdc = retorno sobre o ativo com deemed cost.

Fonte: Elaboração própria.

Em relação ao comportamento das estatísticas descritivas, os resultados encontram-se demonstrados na Tabela 2. Os dados da Tabela 2 mostram que mais da metade das observações do GE, com e sem o custo atribuído, está abaixo da média, conclusão esta obtida em função de que a mediana é inferior à média. Este posicionamento dos dois parâmetros (média e mediana) sugere que uma menor quantidade das firmas da amostra experimentou um endividamento maior não provocado pela adoção do custo atribuído, pois esse endividamento já se apresentava mais alto no cenário sem o custo atribuído, dado que a média foi reduzida de 0,7490 para 0,6505 e a mediana foi também reduzida de 0,6916 para 0,6074.

A relação do comportamento entre o RSA, com e sem o custo atribuído, ao contrário do comportamento do GE, mostra que mais da metade das observações está acima da média, em função de que a mediana é superior à média. Para esses parâmetros, a sinalização é de que o impacto do custo atribuído no ativo e no lucro líquido, este último por meio da depreciação, para uma pequena quantidade de firmas da amostra, foi significativo o suficiente para redução da taxa de retorno, passando de 3,56\% para 1,97\%. Embora seja evidente a contribuição da adição da mais valia do custo atribuído aos itens do imobilizado, pela redução dos parâmetros, ainda não se pode generalizar se essa mais valia no total da amostra é significativa.

Por outro lado, os dados ainda sinalizam que a mostra não segue uma tendência de normalidade, considerando que há um significativo distanciamento entre a média e a mediana. Nesse contexto, observa-se que as maiores dispersões estão localizadas no RSA, que, com a utilização do custo atribuído, o desvio padrão corresponde a 6,77 vezes o valor da média e, sem o custo atribuído, essa relação é de 4,85 vezes, conforme mostra o coeficiente de variação. Em relação ao GE, a dispersão mostra-se menor, reduzindo o distanciamento entre o desvio padrão e a média, pois o primeiro é da ordem de 0,48 vezes, segundo quando incorporado o custo atribuído, e de 0,56 vezes sem a utilização do custo atribuído, também evidenciado pelo coeficiente de variação.

Dessa forma, a magnitude do coeficiente de variação sinaliza que o RSA sem a adição da mais valia do custo atribuído e o GE com essa adição estão com distribuição de frequência mais coesa dentro dos intervalos de variação (mínimo/máximo), enquanto que o RSA com a adição da mais valia do custo atribuído e GE sem essa adição, apresentam menor coesão de frequência no intervalo nos seus respectivos intervalos de variação. 
Tabela 2

\section{Estatística Descritiva do GE e do RA}

\begin{tabular}{lllcc}
\hline \multicolumn{1}{c}{ Parâmetros } & GEsdc & GEcdc & RSAsdc & RSAcdc \\
\hline Média & 0,7490 & 0,6505 & 0,0356 & 0,0197 \\
\hline Mediana & 0,6916 & 0,6074 & 0,0394 & 0,0298 \\
\hline Desvio padrão & 0,4211 & 0,3111 & 0,1726 & 0,1333 \\
\hline Coef de variação & 0,5622 & 0,4782 & 4,8487 & 6,7688 \\
\hline Mínimo & 0,1228 & 0,1559 & $-0,6337$ & $-0,4795$ \\
\hline Máximo & 2,4818 & 1,8435 & 0,7491 & 0,6099 \\
\hline
\end{tabular}

Fonte: Elaboração própria.

O teste utilizado para a comparação das médias do Grau de Endividamento (GE) e do Retorno sobre o Ativo (RSA), com e sem a adoção do custo atribuído, encontra-se demonstrado na Tabela 3, com confiança de $95 \%$. O resultado do teste traz evidências de que, como já sinalizado pelas estatísticas descritivas e coeficientes de correlação, embora quantitativamente as médias sejam diferentes, estatisticamente os escores mostram que não há dispersão significativa suficiente para se admitir que há diferenças entre as médias das variáveis com e sem a utilização do custo atribuído. Essa discussão é sustentada no fato de que a estatística-teste do Retorno sobre o Ativo (RSA) da ordem de 0,5106 e do Grau de Endividamento (GE) da ordem de 0,628 , ambas estão compreendidas bicaudal $\pm 1,96$, o que permite emprestar a interpretação de que o parâmetro $z$ das duas variáveis (estatística-teste) não é significativo, com confiança de $95 \%$.

Mas, por outro lado, se tomadas as estatísticas-teste na forma unicaudal, também se constata que os parâmetros $\boldsymbol{z}(0,628$ e 0,5106$)$ de ambas as variáveis, RSA e GE, estão à esquerda da estatística crítica 1,6449, o que permite também observar que as diferenças não são significativas a $95 \%$ de confiança, estando, portanto inclusas na área de não rejeição que confirmaria hipótese nula da teoria estatística.

Nesse contexto, então, rejeita-se a hipótese alternativa $\left(\mathrm{H}_{1}\right)$ de que as médias são diferentes. Essa assertiva é corroborada pelos resultados dos testes da estatística $F$ mostrados na Tabela 3.1, em que a estatística-teste (calculada) é inferior à estatística $F$ padronizada para os dois indicadores (F calculado 2,01 e 0,30 e F crítico 3,92).

A sinalização da estatística $F$, com valor crítico superior aos valores calculados, é de que as diferenças de médias do GE e do RSA, com e sem a adoção do custo atribuído, não são estatisticamente significativas, confirmando os resultados mostrados pelo teste $z$. Portanto, com base nessa sinalização, o reconhecimento da mais ou menos valia do custo atribuído aos itens do ativo imobilizado das empresas, por ocasião da adoção inicial do padrão IFRS no Brasil, não confirma as expectativas de que a revogação por mais de uma década da autorização de incorporar às demonstrações contábeis das empresas os efeitos inflacionários estaria subavaliando o valor dos ativos.

Tabela 3

Teste-z das médias do GE e do RSA

\begin{tabular}{llll}
\hline \multicolumn{1}{c}{ Parâmetros } & GEsdc & GEcdc & RSAsdc \\
\hline Média & 0,7490 & 0,6505 & 0,0356 \\
\hline Z & 0,6288 & 0,5106 \\
\hline z crítico uni-caudal & 1,6449 & 1,6449 \\
\hline z crítico bi-caudal & 1,96 & 1,96 \\
\hline Fonte: Elaboração própria. & &
\end{tabular}


Tabela 3.1

Teste-F da Variância GE e do RSA

\begin{tabular}{lcccccc}
\hline Fonte da variação GE & SQ & gl & MQ & F & valor-P & F crítico \\
\hline Entre grupos & 0,2767 & 1 & 0,2767 & 2,0187 & 0,1581 & 3,9258 \\
\hline Dentro dos grupos & 15,3492 & 112 & 0,1370 & & & \\
\hline Total & 15,6259 & 113 & & & & \\
\hline \hline Fonte da variação RSA & SQ & gl & MQ & F & valor-P & F crítico \\
\hline Entre grupos & 0,0072 & 1 & 0,0072 & 0,3030 & 0,5831 & 3,9258 \\
\hline Dentro dos grupos & 2,6646 & 112 & 0,0238 & & & \\
\hline Total & 2,6718 & 113 & & & & \\
\hline
\end{tabular}

Fonte: Elaboração própria.

Como os testes demonstrados nas Tabelas 3 e 3.1 sugerem que não há diferenças estatisticamente significativas entre as médias dos indicadores, calculados com e sem a utilização do custo atribuído, com confiança de 95\%, a percepção é de que a soma algébrica da mais ou menos valia do custo atribuído, em média, não provocou impactos significativos no Grau de Endividamento (GE) e no Retorno sobre Ativo (RSA) das empresas, razão pela qual se rejeita a hipótese alternativa de que as médias são diferentes.

Esses resultados dos testes, em princípio, parecem contrariar as expectativas de que a não permissão legal de incorporar os efeitos da inflação nas demonstrações contábeis das empresas brasileiras tributadas pelo lucro real, por mais de uma década, provocaria relevantes variações no ativo e no patrimônio líquido dessas empresas. Essas variações, pelo resultado dos testes, não foram significativas ao ponto de impactarem de forma significativa o quantum dos dois indicadores estruturais eleitos para o teste. Por outro lado, esses resultados não significativos parecem justificar o baixo percentual das empresas que utilizaram o custo atribuído na adoção inicial do padrão IFRS (em torno de 15\%), e que são corroborados também pelo pouco interesse demonstrado por empresas de outros países (20\%, 23\% e 33\%), como confirmam pesquisas anteriores de Aledo, García-Martínez e Diazaraque (2009), Christensen e Nikolaev (2008), Cairns et al. (2011), Cazavan-jeny e Jeanjean (2007).

\section{Considerações Finais}

Como o objetivo da pesquisa é verificar se a utilização do deemed cost (custo atribuído) pelas empresas brasileiras listadas na BM\&Bovespa, por ocasião da adoção inicial do padrão IFRS, no exercício de 2009, teria alterado de forma significativa o Grau de Endividamento (GE) e o Retorno sobre o Ativo (RSA), foi prestigiada adoção de metodologia sustentada em testes quantitativos para verificar as diferenças de médias.

Os resultados dos testes trazem evidências de que, com 95\% de confiança, a utilização do custo atribuído não impactou, significativamente, a informação contábil das 57 empresas da amostra, relativamente aos indicadores estruturais GE e RSA. Esta conclusão está sustentada na resposta dos testes de média e na estatística $F$ que recomendam a rejeição da hipótese alternativa $\left(\mathrm{H}_{1}\right)$. Com essa rejeição, os resultados dos testes permitem concluir que, estatisticamente, não há diferença nas médias do GE e do RSA, ambas calculadas com e sem a mais ou menos valia do custo atribuído.

Esses resultados estão em conformidade com Cotter (1999), que já havia previsto uma desvinculação gradativa do procedimento de reavaliação no sentido de melhorar a composição do Grau de Endividamento. Nessa mesma linha, verifica-se que a baixa atratividade da utilização do custo atribuído pelas empresas brasileiras (em torno de $15 \%$ de adesão) é condizente com o pouco interesse já demonstrado por empresas de outros países $(20 \%, 23 \%$ e $33 \%)$ em pesquisas anteriores divulgadas por Aledo, García-Martínez e Diazaraque (2009), Christensen e Nikolaev (2008), Cairns, Massoudi, Taplin e Tarca (2012), Cazavan-Jeny e Jeanjean (2007). 
Assim, estatisticamente, de forma conclusiva, os resultados dos testes sinalizam que a utilização do custo atribuído pelas empresas brasileiras listadas na BM\&Bovespa, por ocasião da adoção inicial do padrão IFRS, no ano de 2009, não foi atrativo e não provocou impactos relevantes nos indicadores estruturais Grau de Endividamento (GE) e Retorno sobre o Ativo (RSA).

Adicionalmente, os resultados dos testes sinalizam que a revogação legal, por mais de uma década, de incorporar às demonstrações contábeis a perda do poder de compra da moeda provocada pelo processo inflacionário não promoveu subavaliação significativa dos ativos não monetários das empresas brasileiras. Contudo, adverte-se que esta conclusão racionalmente não pode ser generalizada, tendo em vista que as empresas que não são listadas na BM\&Bovespa, por serem de capital fechado, não foram capturadas pela amostra.

\section{Referências}

Aledo, J.; García-Martínez, F. \& Diazaraque, Juan M. M. (2009). Firm-specific factors influencing the selection of accounting options provided by the IFRS: empirical evidence from Spanish Market. Banco da Espanha, Documentos de Trabalho, n. 0926.

Barlev, B.; Fried, D.; Haddad, J. R. \& Livnat, J. (2007). Reevaluation of revaluations: a cross-country examination of the motives and effects on future performance. Journal of Business, Finance and Accounting. 34(7-8), p 1025-1050.

Brown, P.; Izan, H. Y. \& Loh, A. L. (1992). Fixed asset revaluations and managerial incentives. Abacus. 28(1), p. 36-57.

Bruni, A. L.(2011). Estatística aplicada a gestão empresarial. (3 ed.), São Paulo: Atlas.

Cairns, D.; Massoudi, D.; Taplin, R. \& Tarca, A. (2011).IFRS fair value measurement and accounting policy choice in the United Kingdom and Australia. The British Accounting Review, 43(1), p. 1-27.

Cazavan-Jeny, A. \& Jeanjean, T. (2011). Accounting choices under IFRS 1: Analysis and determinants. Journal of Accounting and Public Policy, 30(2), p. 145-165.

Cotter, J. (1999). Asset revaluation and debt contracting. Abacus. 35(3), p. 268-285.

Christensen, H. B. \& Nikolaev, V. (2008). Who uses fair-value accounting for non-financial assets following IFRS adoption? Recuperado em 26 setembro, 2012, de http://ssrn.com/abstract=1269515.

Comitê de Pronunciamentos Contábeis - 28 (2009a) Pronunciamento Técnico CPC 27 - Ativo Imobilizado. Recuperado em 11 setembro, 2012 de http://cpc.org.br/pdf/CPC\%2027.pdf .

Comitê de Pronunciamentos Contábeis - CPC (2010a). Pronunciamento Técnico CPC 37 (R1) - Adoção Inicial das Normas Internacionais de Contabilidade. Recuperado em 11 setembro, 2012, de http:// www.cpc.org.br/pdf/CPC37_R1_final.pdf.

Comitê de Pronunciamentos Contábeis - CPC. (2010b) Pronunciamento Técnico CPC 43 (R1) - Ativo Adoção Inicial dos Pronunciamentos Técnicos CPC 15 a 41. Recuperado em 11 setembro, 2012, de http:// www.cpc.org.br/pdf/CPC43_R1.pdf.

Comitê de Pronunciamentos Contábeis - CPC (2009b). Interpretação técnica ICPC 10. Recuperado em 11

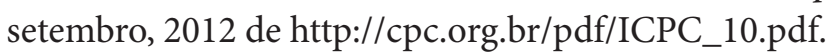

Demaria, S. \& Durfour, D. (2007). First time adoptionof IFRS, Fair valueoption, Conservatism: EvidencesfromFrenchlistedcompanies. Recuperado em 15 Setembro, 2012, de http://hp.gredeg.cnrs.fr/demaria/recherche/First\%20adoption\%20and20fair\%20value\%20Demaria\%20Dufour.pdf .

Easton, P. D.; Eddey, P. H. \& Harris, T. S. (1993). An investigation of revaluations of tangible long-lived assets. Journal of Accounting Research. l(31), p. 1-38. 
Fields, T. D.; Lys, T. Z. \& Vincent, L. (2000). Empirical research on accounting choice. Journal of Accounting and Economics, 31, p. 255-307.

Heflin, F.; Kwon, S. S. \& Wild, J.J. (2002). Accounting choices: variation in managerial opportunism. Journal of Business Finance and Accounting, 29, p. 1047-1077.

ICAEW (2007). Financial reporting faculty. EU Implementation of IFRS and the Fair Value Directive, Recuperado em 11 setembro, 2012, de http://ec.europa.eu/internal_market/accounting/docs/ studies/2007-eu_implementation_of_ifrs.pdf.

International Accounting Standard Board (IASB) (2003) IFRS 01 - First Time Adoption of International Financial Reporting Standard. Recuperado em 11 setembro, 2012, de http://www.ifrs.org/IFRSs/ Pages/IFRS.aspx

Lei 9.249, de 26 de dezembro de 1995 (1995). Altera a legislação do imposto de renda das pessoas jurídicas, bem como da contribuição social sobre o lucro líquido, e dá outras providências. Diário Oficial da União, Brasília, DF

Lei 9.638, de 28 de dezembro de 2007 (2007). Altera e revoga dispositivos da Lei no 6.404, de 15 de dezembro de 1976, e da Lei no 6.385, de 7 de dezembro de 1976, e estende às sociedades de grande porte disposições relativas à elaboração e divulgação de demonstrações Diário Oficial da União, Brasília, DF

Lopes, A. B. \& Walker, M. (2010). Asset revaluations, future firm performance and firm-level corporate governance arrangements: new evidence from Brazil? The British Accounting Review, 44(2)., p. 5367. DOI:10.1016/j.bar.2012.03.007

Missio, F. \& Jacobi, L. F.(2007). Variáveis dummy: especificações de modelos com parâmetros variáveis. Ciência e Natura, 29(1), p. 111-135.

Missonier-Piera, F. (2007). Motives for fixed-asset revaluation: an empirical analysis with Swiss data. The International Journal of Accounting 42, p. 186-205.

Parlamento Europeu \& Conselho da União Europeia (2002). Regulamento (CE) No 1.606/02. Diario official das comunidades europeias, L/243/1. Recuperado em 11 setembro, 2012, de http://www.cnc. min-financas.pt/pdf/IAS_IFRS_UE/Reg_1606_02_IAS_pt.pdf.

Watts, R. L. (1992). Accounting choice theory and market-based research in accounting. British Accounting Review, 24, p. 235-267.

Waweru, N. M.; Ntui, P. P. \& Mangena, M. (2010). Determinants of different accountingmethods choice in Tanzania: A positive accounting theory approach. Journal of Accountingin Emerging Economies, $1(2)$, p.144-159. 


\section{Apêndice}

GE e RSA das 57 empresas listadas na BM\&BOVESPA que utilizaram o custo atribuído na adoção inicial do padrão IFRS no Brasil em 2009

\begin{tabular}{|c|c|c|c|c|}
\hline \multirow[b]{2}{*}{ Empresa } & \multicolumn{2}{|c|}{ Sem custo atribuído } & \multicolumn{2}{|c|}{ Com custo atribuído } \\
\hline & GE & RSA & GE & RSA \\
\hline E_1 & 1,1452 & 0,0137 & 0,8306 & 0,0071 \\
\hline E_2 & 0,7774 & 0,3467 & 0,5623 & 0,1386 \\
\hline E_3 & 0,4318 & 0,0394 & 0,4255 & 0,0367 \\
\hline E_4 & 0,7495 & 0,0186 & 0,6636 & 0,0131 \\
\hline E_5 & 1,4026 & 0,7491 & 1,2051 & 0,6099 \\
\hline E_6 & 0,4647 & 0,023 & 0,4595 & 0,0172 \\
\hline E_7 & 0,806 & 0,0255 & 0,7434 & 0,0221 \\
\hline E_8 & 0,4633 & 0,0078 & 0,429 & $-0,0008$ \\
\hline E_9 & 0,6025 & 0,0293 & 0,5895 & 0,0264 \\
\hline E_10 & 0,8269 & 0,0847 & 0,6074 & 0,0298 \\
\hline E_11 & 0,644 & 0,0645 & 0,6264 & 0,052 \\
\hline E_12 & 0,4776 & 0,0467 & 0,453 & 0,0181 \\
\hline E_13 & 0,2057 & 0,1716 & 0,2078 & 0,1703 \\
\hline E_14 & 0,7335 & 0,0338 & 0,2086 & 0,0002 \\
\hline E_15 & 0,3617 & 0,0742 & 0,3582 & 0,0497 \\
\hline E_16 & 0,4704 & 0,1132 & 0,419 & 0,0562 \\
\hline E_17 & 1,0737 & $-0,5149$ & 1,0193 & $-0,4795$ \\
\hline E_18 & 0,1883 & 0,0131 & 0,242 & $-0,0047$ \\
\hline E_19 & 0,3968 & 0,1742 & 0,3912 & 0,157 \\
\hline E_20 & 1,8541 & $-0,3062$ & 1,4256 & $-0,2472$ \\
\hline E_21 & 0,826 & 0,0349 & 0,8055 & 0,0328 \\
\hline E_22 & 0,5779 & 0,0586 & 0,5527 & 0,0455 \\
\hline E_23 & 0,5543 & 0,0832 & 0,5222 & 0,0588 \\
\hline E_24 & 0,339 & 0,0944 & 0,3391 & 0,0809 \\
\hline E_25 & 1,1543 & 0,0119 & 0,7562 & 0,0061 \\
\hline E_26 & 0,4688 & 0,0694 & 0,4542 & 0,0505 \\
\hline E_27 & 0,8772 & 0,0193 & 0,8638 & 0,0173 \\
\hline E_28 & 0,8112 & 0,0334 & 0,7446 & 0,0307 \\
\hline E_29 & 0,7867 & 0,0304 & 0,7188 & 0,0258 \\
\hline E_30 & 0,7015 & 0,0416 & 0,6384 & 0,0344 \\
\hline E_31 & 0,6916 & 0,0646 & 0,663 & 0,0594 \\
\hline E_32 & 0,7631 & 0,0397 & 0,7407 & $-0,0028$ \\
\hline E_33 & 0,6346 & 0,0593 & 0,5996 & 0,0522 \\
\hline E_34 & 0,5886 & 0,0393 & 0,5447 & $-0,0091$ \\
\hline E_35 & 1,9378 & $-0,6337$ & 1,335 & $-0,4175$ \\
\hline E_36 & 0,4311 & 0,043 & 0,3337 & 0,0333 \\
\hline E_37 & 0,5882 & 0,0321 & 0,5713 & 0,0179 \\
\hline E_38 & 0,7207 & 0,0369 & 0,6718 & 0,032 \\
\hline E_39 & 0,9653 & 0,1808 & 0,6532 & 0,06 \\
\hline E_40 & 0,6569 & 0,0539 & 0,6263 & 0,0416 \\
\hline
\end{tabular}




\begin{tabular}{ccccc} 
& \multicolumn{2}{c}{ Sem custo atribuído } & \multicolumn{2}{c}{ Com custo atribuído } \\
\cline { 2 - 5 } Empresa & GE & RSA & GE & RSA \\
\hline E_41 & 0,9033 & 0,0017 & 0,9012 & 0,0001 \\
\hline E_42 & 1,0185 & 0,1699 & 0,7531 & 0,0839 \\
\hline E_43 & 0,754 & 0,0675 & 0,6767 & 0,0279 \\
\hline E_44 & 0,4866 & 0,0071 & 0,4756 & 0,0021 \\
\hline E_45 & 0,7193 & 0,0174 & 0,6786 & 0,0145 \\
\hline E_46 & 0,6564 & 0,0688 & 0,5643 & 0,0477 \\
\hline E_47 & 1,2811 & $-0,1353$ & 1,1472 & $-0,1201$ \\
\hline E_48 & 0,1228 & 0,0858 & 0,1559 & 0,0552 \\
\hline E_49 & 2,4818 & $-0,1352$ & 1,8435 & $-0,101$ \\
\hline E_50 & 0,6187 & 0,1175 & 0,5888 & 0,0942 \\
\hline E_51 & 0,5176 & 0,0317 & 0,4736 & 0,011 \\
\hline E_52 & 0,3307 & $-0,0532$ & 0,3355 & $-0,0391$ \\
\hline E_53 & 0,8495 & 0,0778 & 0,8225 & 0,0711 \\
\hline E_54 & 0,5603 & 0,1021 & 0,5159 & 0,0668 \\
\hline E_55 & 0,8795 & 0,0006 & 0,8765 & 0,0004 \\
\hline E_56 & 1,1074 & $-0,0497$ & 0,9974 & $-0,0515$ \\
\hline E_57 & 0,2562 & 0,0539 & 0,2701 & 0,0377 \\
\hline
\end{tabular}

Fonte: Autor.

Cálculos produzidos com base nos dados primários das demonstrações financeiras padronizadas utilizando as equações (3) e (4). 